Article

\title{
Optimizing Recovery of Hybrid Embryos from Interspecific Citrus Crosses of Polyembryonic Rough Lemon (Citrus jambhiri Lush.)
}

\author{
Jagveer Singh ${ }^{1, *(1)}$, Harvinder Singh Dhaliwal ${ }^{2, *}$, Anirudh Thakur ${ }^{2}$, Gurupkar Singh Sidhu ${ }^{1}$, \\ Parveen Chhuneja ${ }^{1}$ and Frederick G. Gmitter Jr. ${ }^{3}$ (D) \\ 1 School of Agricultural Biotechnology, Punjab Agricultural University, Ludhiana 141004, India; \\ gurupkar-soab@pau.edu (G.S.S.); pchhuneja@pau.edu (P.C.) \\ 2 Department of Fruit Science, Punjab Agricultural University, Ludhiana 141004, India; \\ anirudhthakur@pau.edu \\ 3 Citrus Research and Education Center, University of Florida, 700 Experiment Station Road, Lake Alfred, \\ FL 33850, USA; fgmitter@ufl.edu \\ * Correspondence: jagveer-coafs@pau.edu (J.S.); dhaliwal_mandhali@pau.edu (H.S.D.)
}

Received: 28 October 2020; Accepted: 4 December 2020; Published: 10 December 2020

check for updates

\begin{abstract}
The prevalence of rough lemon rootstock in India is presently threatened by the spread of Phytophthora root rot. Developing an alternative Phytophthora-resistant rootstock that also withstands other abiotic constraints is a priority for a sustainable citrus industry in India. Complementary progenitors can be found in citrus germplasm to combine the desired traits, particularly between Citrus and Poncirus, a closely related genus. The production of hybrids accumulating the desired dominant traits, irrespective of the heterozygosity level of the parents, is an effective way to develop new candidate rootstocks. Rough lemon was hybridized with Swingle citrumelo, X-639 citrandarin, and GouTou Cheng. A reliable method was developed for greater recovery of hybrid seedlings from these crosses on the basis of morphology and simple sequence repeat (SSR) markers. The greatest proportion of hybrid seedlings resulted from embryo rescue at 95 days after pollination (DAP) (48.5\% in rough lemon $\times$ X-639 citrandarin and $56.7 \%$ in rough lemon $\times$ Swingle citrumelo) on the basis of multifoliate leaves. The proportion of hybrid seedlings decreased with increase in embryo development stage after 95 DAP until the last stage of observation (125 DAP). Significantly higher proportion of multifoliate seedlings was recovered by in vitro culture compared with in vivo germination from the mature seeds (26.9\% vs. $5.2 \%$, respectively). Swingle and X-639 citrandarin are not homozygous for the multifoliate allele from Poncirus, and GouTou Cheng lacks the multifoliate allele; thus, unifoliate hybrids were selected from all crosses on the basis of SSR marker genotypes.
\end{abstract}

Keywords: embryo rescue; citrus rootstock breeding; organic adjuvant; gibberellic acid; hybrids and SSR markers

\section{Introduction}

Globally, citrus fruits are grown over an area of 8.9 million ha with 137.8 million tons of production. China, with 34.9 million tons of production, is the major producer of citrus fruits, followed by Brazil (19.1 million tons), India (11.15 million tons), the USA (8.5 million tons), and Mexico (7.8 million tons) [1]. Owing to tolerance of citrus tristeza virus (CTV), suitability to high $\mathrm{pH}$ soils and high scion yields, rough lemon is a major citrus rootstock in India. However, rough lemon rootstock is highly susceptible to Phytophthora root rot, which affects tree performance and longevity and imparts poor fruit quality to the scion varieties. Several hybrids of trifoliate orange (Poncirus trifoliata L. Raf), namely, citranges (sweet orange $\times$ trifoliate orange), X-639 citrandarin (Cleopatra mandarin $\times$ trifoliate orange), 
and Swingle citrumelo (Duncan grapefruit $\times$ trifoliate orange), which are tolerant to Phytophthora, are widely used as citrus rootstocks globally [2]. However, these rootstocks are not suitable for Indian conditions because of alkaline, saline, and heavy soils. Many hybrid rootstocks involving trifoliate orange, namely, citranges and citrumelos, performed better than their parents, but they need improvement for adaptation under saline and calcareous soils [3].

Trifoliate orange is tolerant to Phytophthora as well as cold stress, and it can sometimes support smaller trees producing better fruit quality [4]. Crossing rough lemon with various trifoliate oranges and their hybrids can be a viable strategy to develop new locally adaptable tree size-controlling citrus rootstocks tolerant to Phytophthora. Sexual hybridization in most citrus species is complicated because of its complex reproductive biology. Citrus cultivars are mostly heterozygous and polyembryonic, although some important traits show single-gene inheritance patterns [5-7]. Polyembryony interferes with zygotic embryo recovery and impairs creation of large segregating populations for selection; therefore, achievement of desired characteristics is complicated, even when using complementary parents. Nucellar embryos are more vigorous and inhibit the full development of the zygotic embryo and cause its degeneration prior to seed maturation [8]. Nucellar embryos limit the range of genetic variability that can be observed in the progeny of a cross and the possibility of finding new genotypes.

Embryo rescue can be a useful tool for recovery of hybrid embryos in citrus sexual breeding [9]. It has been successfully used to obtain diploid hybrids from crosses between polyembryonic cultivars [10]. The success of embryo culture is largely determined by the stage of embryo rescue, the ingredients of media used for culturing, and the genotype of the plant [11,12]. The germination capacity of hybrid embryos can be affected by the embryo's genetic potential and stage of development [13]. The stage of embryo rescue has been reported to vary with the genotype of the parents.

In citrus, occurrence of polyembryony obscures the clear identification of zygotic seedlings in citrus. Despite polyembryony, every seed generally generates only one or few vigorous seedlings under in vivo conditions. In vitro culture of mature seeds allows for the germination of a large number of embryos (up to 20-25 seedlings per seed) and potentially high recovery of hybrids, but zygotic embryos may fail to survive until fruit maturation. In vitro culture of mature seeds enables rescue of zygotic embryo otherwise aborted due to competition of rival nucellar embryos. In the crosses involving Citrus sunki and two trifoliate oranges, Zhu et al. [4] recovered hybrid seedlings with in vitro culture of embryos from mature fruits. However, they could not recover any hybrid seedling by sowing the seed from mature fruits in soil. Early identification of hybrid seedlings allows for the elimination of unwanted nucellar embryo-derived plantlets to save land and cost. Citrus hybrids from crosses with trifoliate orange generally display multifoliate leaves at an early stage of development. When trifoliate orange hybrids are backcrossed with citrus, the number of seedlings showing multifoliate leaves varied, making it an unreliable marker for the identification of zygotic seedlings [14]. Molecular markers are alternative tools that can unmistakably identify zygotic seedlings as they are not influenced by environment [4]. Simple sequence repeat (SSR) markers reveal high levels of polymorphism due to variation in the number of repeat units at a locus. SSR markers have been used to identify the zygotic seedlings in crosses between tangor and sweet orange [15], mandarin and trifoliate orange crosses [10], and mandarin (Citrus reticulata Blanco) and pummelo (Citrus maxima Merr.) crosses [16]. Single-nucleotide polymorphism (SNP) markers have been used for the identification of zygotic seedlings in hybrids involving trifoliate orange [4,14]; however, SNP marker technology is costly and not applicable in every laboratory [17].

The present studies were conducted to determine the effect of genotypes, embryo development stage, tissue culture media, and supplementation of media with malt extract and $\mathrm{GA}_{3}$ on the recovery of hybrid embryos. Moreover, molecular markers able to distinguish zygotic from the nucellar seedlings from the cross combinations between rough lemon as seed parent and X-639 citrandarin, Swingle citrumelo, and GouTou Cheng sour orange as pollen parents were also identified. 


\section{Materials and Methods}

\subsection{Plant Material}

Rough lemon (RL) trees on rough lemon rootstock were propagated with scion buds from a single elite rough lemon tree planted in College Orchard, Department of Fruit Science, Punjab Agricultural University, Ludhiana, India, located at $29.3^{\circ} \mathrm{N}$ latitude and $76.5^{\circ} \mathrm{E}$ longitude, $270 \mathrm{~m}$ above mean sea level (amsl). Artificial pollination was performed at College Orchard from 9th March to 27th March 2015. Rough lemon (Citrus jambhiri Lush.) flowers at popcorn (before anthesis) stage were pollinated with the pollen of X-639 citrandarin (X; Cleopatra mandarin $\times$ trifoliate orange), Swingle citrumelo (SC; Duncan grapefruit $\times$ trifoliate orange), and GouTou Cheng sour orange (GT). We attempted 1745 crosses in $\mathrm{RL} \times \mathrm{X}, 1706$ in $\mathrm{RL} \times \mathrm{SC}$, and 765 in $\mathrm{RL} \times \mathrm{GT}$.

\subsection{Embryo Rescue and Plant Recovery}

Experiments were initiated to determine the influence of integuments on embryos excised without cotyledon from immature seeds and to know the influence of seed coat on mature seed germination under in vivo condition. Embryos were isolated with cotyledon from mature seeds with the aid of forceps and surgical blade under 10x magnification using a stereomicroscope (Axio Scope. A1, Zeiss Pvt. Ltd., Jena, Germany) under in vitro conditions. Immature fruits of RL $\times$ X, RL $\times$ SC, and RL $\times$ GT were collected at $65,80,95,110$, and 125 days after pollination (DAP) for in vitro culture, and mature fruits from RL $\times$ X and RL $\times$ SC at 190 DAP for in vitro and in vivo culture were surface-sterilized with mercuric chloride $(0.1 \%)$ for $2 \mathrm{~min}$, followed by 3 washings with sterile distilled water to remove the toxic effects of mercuric chloride. Finally, the fruits were treated with 70 per cent ethanol for 5 min and then flamed. The sterilized fruits were cut with a sharp blade at the equatorial zone, avoiding the core where seeds are embedded. Both halves of the fruit were twisted in opposite directions until total separation of halves and seeds were squeezed into a Petri plate. Excised embryos were immediately plated on different nutrient media to induce germination. All the embryos from a seed were cultured on a single Petri plate. After 4 weeks, the germinated seedlings from the embryos were transferred to the same media in a tissue culture vessel $(470 \mathrm{~mL})$ to induce plant growth. The cultured Petri plates and tissue culture vessels were incubated at $25 \pm 2{ }^{\circ} \mathrm{C}$ with $16 \mathrm{~h}$ of continuous fluorescent light (5000 lux), followed by $8 \mathrm{~h}$ of dark period.

\subsection{Culture Media}

The excised embryos from immature seeds were cultured on Murasige and Skooge medium (MS) [18] and Woody Plant medium (WP) [19] fortified with 4 levels of malt extract (ME). Sucrose $(50 \mathrm{~g} / \mathrm{L})$ and agar $(7.5 \mathrm{~g} / \mathrm{L})$ were also added to the media. In addition, gibberellic acid $\left(\mathrm{GA}_{3}\right), 0.1 \mathrm{mg} / \mathrm{L}$, was added into the MS media, along with 4 concentrations of malt extract to compare the effect of addition of $\mathrm{GA}_{3}$. However, $\mathrm{GA}_{3}$ was not tested with WPM, as this media had not shown a good response in our earlier experiments (unpublished data). The $\mathrm{pH}$ of the media was adjusted to 5.8 with pH meter (Century CP 931, Chandigarh) using $1 \mathrm{~N} \mathrm{HCl}$ or $1 \mathrm{~N} \mathrm{NaOH}$ before adding agar. The media was sterilized in an autoclave at $121^{\circ} \mathrm{C}$ for $20-25 \mathrm{~min}$ and was dispensed in $55 \mathrm{~mm}$ Petri plates. In total, 12 media combinations were tested for their effect on embryo rescue, hybrid recovery, and seedling growth at 5 different fruit developmental stages (Table 1).

Table 1. Media combinations used for the initial establishment of embryo rescue.

\begin{tabular}{cccccccccccccc}
\hline \multicolumn{2}{c}{ Media } & M1 & M2 & M3 & M4 & G1 & G2 & G3 & G4 & W1 & W2 & W3 & W4 \\
\hline \multicolumn{2}{c}{ Basal Medium } & \multicolumn{1}{c}{ MS } \\
\hline \multirow{2}{*}{ Growth regulators } & GA $_{3}(\mathbf{m g} / \mathbf{L})$ & - & - & - & - & 1.0 & 1.0 & 1.0 & 1.0 & - & - & - & - \\
& ME(g/L) & 0.25 & 0.5 & 0.75 & 1.0 & 0.25 & 0.5 & 0.75 & 1.0 & 0.25 & 0.5 & 0.75 & 1.0 \\
\hline
\end{tabular}

MS: Murasige and Skooge medium, WPM: woody plant medium, $\mathrm{GA}_{3}$ : gibberellic acid, ME: malt extract. Sucrose $(50 \mathrm{~g} / \mathrm{L})$ was added to the media and $\mathrm{pH}$ was adjusted to 5.8 , then autoclaved at $121^{\circ} \mathrm{C}$. 


\subsection{Hardening and In Vivo Transfer}

After 50 days of subculture, the embryos were taken out from the culture vessels and washed carefully to remove the traces of media present on the roots. The plantlets were transplanted in root trainer trays (300 cc cell) filled with steam-sterilized hardening medium (cocopeat/vermiculite/perlite, 2:1:1) after dipping the roots in $2 \%$ carbendazim 50 DF (Bavistin 50 DF, BASF) fungicide solution. The root trainer trays were kept in a temperature-controlled growth chamber (Rinac India Ltd., New Delhi, India) at $24 \pm 2{ }^{\circ} \mathrm{C}$ with $85-90 \%$ relative humidity for hardening of the seedlings. After 2 weeks of acclimatization, the seedlings with unifoliate and multifoliate leaves were transplanted in black polythene bags $(30 \times 15 \mathrm{~cm})$ filled with growing medium (soil/FYM/cocopeat, 2:1:1) and transferred to a green shade net house ( $50 \%$ shade) at $4-5$ leaf stage. The data regarding survival percentage of seedlings were recorded 30 days after transfer in the growing medium.

\subsection{SSR Analysis}

Genomic DNA from each plant was extracted from bulked leaf samples using the method of Doyle and Doyle [20] with certain modifications. The principle modification was the use of sodium acetate anhydrous $(3.5 \mathrm{M})$ along with isopropanol during the DNA extraction to prevent browning of the supernatant. The extracted DNA was quantified using a Nanodrop 1000 instrument (Thermo Scientific, Wilmington, NC, USA) and used for PCR amplification. The purified DNA, approximately $30 \mathrm{ng}$, was used for amplification with SSR primers in polymerase chain reaction (PCR). Amplification was carried out in a $10 \mu \mathrm{L}$ reaction mixture (2.5 mM Taq buffer, $1.5 \mathrm{mM} \mathrm{MgCl}$, $0.2 \mathrm{mM}$ deoxynucleoside triphosphate dNTPs, $0.4 \mu \mathrm{M}$ primer, and 1.0 $\mathrm{U}$ of Taq DNA polymerase) in a gradient thermocycler (Veriti 96-Well Thermal Cycler, Applied Biosciences, Invitrogen, United Kingdom). The PCR amplification for SSR markers was achieved using thermal profile of initial denaturation at $94{ }^{\circ} \mathrm{C}$ for $4 \mathrm{~min}$, followed by 35 cycles of denaturation at $94{ }^{\circ} \mathrm{C}$ for $1 \mathrm{~min}$, annealing at 58-60 ${ }^{\circ} \mathrm{C}$ (primer-specifc) for $1.30 \mathrm{~min}$ and extension at $72{ }^{\circ} \mathrm{C}$ for $1.30 \mathrm{~min}$, and final extension at $72{ }^{\circ} \mathrm{C}$ for $7 \mathrm{~min}$. PCR products were separated through $6 \%$ PAGE using PAGE apparatus (Mega-Gel System) of CBS Scientific, USA (C-DASG-400-50), and visualized under UV light in gel documentation (SYNGENE, G: Box, USA). The SSR amplicons were recorded in a binary matrix as 1 (band present) and 0 (band absent). Total number of alleles for each primer was then scored in all the accessions under study. The SSR primers used in the present study were selected from the previous studies [21-25] used for citrus germplasm characterization and hybridity confirmation.

\subsection{Confirmation of Zygotic Seedlings by SSR}

After embryo rescue from immature seeds, only hybrid seedlings from $R L \times X$ and $R L \times S C$ crosses were screened by SSR markers; 284 seedlings from $\mathrm{RL} \times \mathrm{X}$ cross and 318 from $\mathrm{RL} \times \mathrm{SC}$ cross exhibited the bifoliate, trifoliate, and unifoliate phenotype of the pollen parents (X-639 citrandarin and Swingle citrumelo). Twenty-seven multifoliate plants were identified among $R L \times X$, and 33 in $R L \times S C$ progenies. A total of 1028 seedlings emerged from the 436 mature seeds (444 in RL $\times$ X and 584 in $\mathrm{RL} \times \mathrm{SC}$ ). The trifoliate leaf trait, a monogenic dominant character that distinguished most trifoliate orange cultivars, is a classic feature used as morphological marker for hybrids screening [26]. Five sets of SSR primers (F29, F87, TAA1, CCSMEc4, and CCSME31) revealed the highest level of polymorphism out of the 55 SSR markers used for diversity analysis and hybrid confirmation in our ongoing rough lemon improvement work. All seedlings that showed multifoliate leaves were screened with two SSR markers (F29 and F87) for confirmation of hybridity. One hundred and sixty unifoliate seedlings from 100 mature seeds from RL $\times$ X and RL $\times$ SC crosses were screened with five SSR markers (F29, F87, TAA1, CCSMEc4, and CCSME31) to confirm hybridity. 


\subsection{Experimental Design and Statistical Analysis}

In each experiment, 10 immature seeds were cultured on the 12 culture media each at $65,80,95$, 110 , and 125 DAP. Twenty-five mature seeds in vitro and 50 mature seeds in vivo at $190 \mathrm{DAP}$ were cultured with 3 replications. The data pertaining to the number of embryos per seed were recorded for each cross at all the fruit developmental stages at the time of culturing. Embryo germination was recorded 4 weeks after culture in Petri plates. Shoot length, number of leaves, number of roots, and root length were recorded 50 days after transfer of the seedlings in the tissue culture jars. The analysis of variance and separation of means following significant F-test was performed by least significant difference (LSD) or $t$-test statistics using SAS (9.4 version) computer software. If necessary, the data were transformed to achieve homogeneity of variances, prior to analysis.

\section{Results and Discussion}

\subsection{Number of Embryos and Plant Recovery}

The crosses $(\mathrm{RL} \times \mathrm{X}, \mathrm{RL} \times \mathrm{SC}$, and $\mathrm{RL} \times \mathrm{GT})$ significantly differed for the average number of embryos per seed, with higher number of embryos per seed recorded in RL $\times$ SC (5.3) in comparison to 4.4 in $\mathrm{RL} \times \mathrm{X}$ and 3.6 in RL $\times$ GT. In all the crosses, the minimum numbers of embryos were recorded at $65 \mathrm{DAP}(2.0,2.6$, and 1.7 for $\mathrm{RL} \times \mathrm{X}, \mathrm{RL} \times \mathrm{SC}$, and $\mathrm{RL} \times \mathrm{GT}$, respectively), which reached the maximum values of 5.6, 6.7, and 8.1 for $R L \times G T, R L \times S C$, and $R L \times X$, respectively, at 95 DAP (Table 2). After $95 \mathrm{DAP}$, the number of embryos per seed decreased until the last observation (125 DAP). Citrus exhibited a high degree of apomixis, and thus identification of zygotic seedlings is the major obstacle in its improvement especially in crosses involving closely related parents [27]. Perez-Tornero and Porras [28] studied 27 lemon cultivars and considered them slightly or moderately polyembryonic, with 25 to $43 \%$ of seeds being polyembryonic (1.3 to 1.6 embryos per seed). Zhu et al. [4] crossed Shantou-Suanju (Citrus sunki Hort. ex. Tan.) with two trifoliate orange (P. trifoliata) varieties Monstrosa and Xiaoganzhi for breeding new citrus rootstocks and did not report any effect of the pollen parent on the number of embryos, whereas Jaskani et al. [12] found a strong effect of pollen parent on number of embryos per seed and number of seeds per fruit in citrus. They also reported that in hybrid fruits, underdeveloped seeds had poorly developed endosperm, which could result in embryo abortion of the hybrid fruits. Many researchers have reported varied number of days after pollination (DAP) for higher embryo recovery in different citrus species, varying from 80-150 DAP, namely, 80 DAP in mandarin $\times$ trifoliate orange [10], 105 DAP in Femminello lemon cybrids ( $2 \mathrm{n}$ and $4 \mathrm{n}$ ) and a diploid clone of Femminello lemon (Citrus limon L. Burm. F.) [29], 115 DAP in Cleopatra mandarin $\times$ Carrizo citrange and Cleopatra mandarin $\times$ Flying Dragon [30], 118 DAP in Pera Rio Sweet orange $\times$ Ponca mandarin [31], 120 DAP in common sour orange [32], and 135-150 DAP in lemon [28].

Table 2. Recovery of zygotic embryos at different time intervals from three crosses.

\begin{tabular}{|c|c|c|c|c|c|c|c|c|c|c|}
\hline \multirow{2}{*}{ Growing Conditions } & \multirow{2}{*}{ DAP } & \multicolumn{3}{|c|}{$\mathbf{R L} \times \mathbf{X}$} & \multicolumn{3}{|c|}{$\mathbf{R L} \times \mathbf{S C}$} & \multicolumn{3}{|c|}{$\mathbf{R L} \times \mathbf{G T}$} \\
\hline & & A & B & Zygotic \% & A & B & Zygotic \% & A & B & Zygotic \% \\
\hline \multirow{6}{*}{ In vitro } & 65 & 36 & $2.6 \pm 0.2$ & 22.2 & 29 & $2.0 \pm 0.1$ & 24.1 & 24 & $1.7 \pm 0.8$ & 29.2 \\
\hline & 80 & 35 & $4.2 \pm 0.5$ & 34.4 & 26 & $6.5 \pm 0.1$ & 30.9 & 29 & $3.4 \pm 0.5$ & 27.6 \\
\hline & 95 & 31 & $6.7 \pm 0.5$ & 48.5 & 30 & $8.1 \pm 1.0$ & 56.7 & 20 & $5.6 \pm 1.1$ & 60.0 \\
\hline & 110 & 30 & $4.3 \pm 0.5$ & 33.3 & 28 & $5.6 \pm 0.6$ & 39.3 & 30 & $4.2 \pm 0.7$ & 23.3 \\
\hline & 125 & 32 & $4.0 \pm 0.4$ & 25.0 & 36 & $4.4 \pm 0.4$ & 36.1 & 25 & $3.3 \pm 0.5$ & 28.0 \\
\hline & 190 & 75 & $3.9 \pm 0.4$ & 27.7 & 90 & $3.6 \pm 0.3$ & 31.1 & - & - & - \\
\hline In soil & 190 & 150 & $2.0 \pm 0.2$ & 6.7 & 150 & $2.5 \pm 0.2$ & 3.7 & - & & - \\
\hline
\end{tabular}

DAP: days after pollination, A: seeds, B: embryo/seed. Data are means \pm standard error, significant differences $(p<0.05)$ according to the least significant difference (LSD) test, for the mean number of embryos per seed. 


\subsection{Embryo Germination}

Comparison between In Vitro and In Vivo Germination

All the embryos with cotyledons from a mature seed were cultured in a single Petri dish in MS medium [18] supplemented with malt extract (ME; $750 \mathrm{mg} / \mathrm{L})$, sucrose $(50 \mathrm{~g} / \mathrm{L})$, and agar $(7.5 \mathrm{~g} / \mathrm{L})$ to induce germination. For in vivo germination, the seeds were sown in root trainer trays (300 cc cell) filled with growing medium (nursery soil/FYM/cocopeat, 2:1:1) after removal of seed coat (Figure 1).

Germination percentage of immature hybrid embryos under in vitro condition was significantly affected by embryo developmental stage and culture media (Tables 3 and 4). In all the cross combinations, embryo germination percentage increased with the stage of embryo culture from 65 to 95 DAP, irrespective of the culture media. The highest average embryo germination was $81.2 \%$ for $\mathrm{RL} \times \mathrm{GT}$, $83.0 \%$ for $\mathrm{RL} \times \mathrm{X}$, and $84.5 \%$ for $\mathrm{RL} \times \mathrm{SC}$ at $95 \mathrm{DAP}$, which significantly decreased thereafter until the last culture at 125 DAP.

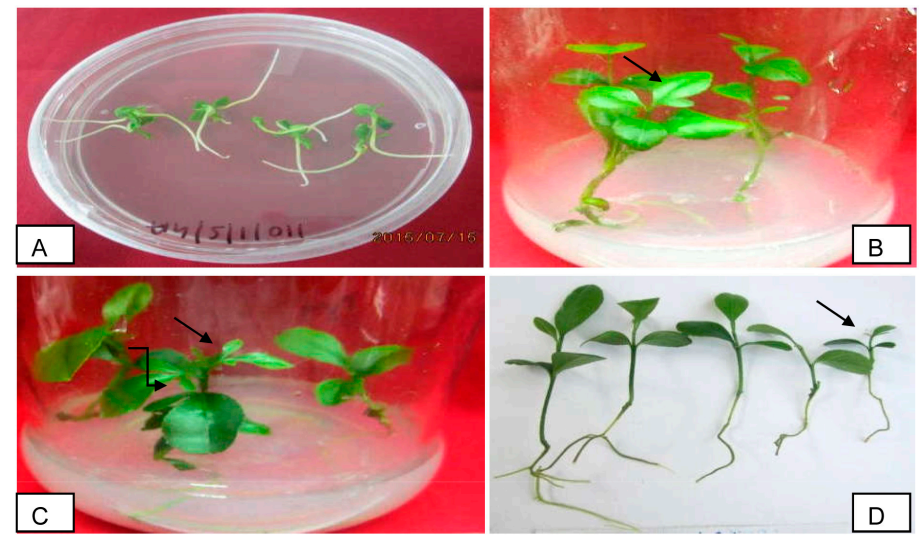

Figure 1. In vitro zygotic embryo germination in $\mathrm{RL} \times \mathrm{SC}$; (A) In vitro germinated embryo with well developed root on MS + ME (0.75 g/L) + GA $3(1.0 \mathrm{mg})+$ Sucrose $(50 \mathrm{~g} / \mathrm{L}),($ B) plantlets with entire and bifoliate leaf, (C) plantlets with entire and trifoliate leaves, (D) seedlings after 40 to 50 days in the growth medium with entire and trifoliate leaves and arrows indicated bifoliate and trifoliate plantlets.

The lowest embryo germination was observed at 65 DAP, indicating immaturity of embryos. The embryo rescue stage is an important factor for zygotic seedling recovery, which depends on the stage of embryo abortion or the time of nucellar embryo invasion [10]. Perez-Tornero and Porras [28] observed visible embryos at 50, 65, and 80 days after anthesis (DAA) in Eureka lemon, however, the highest embryo survival was recorded when embryos were rescued from 100 to 150 DAA. The appropriate stage for embryo rescue varied on the basis of the genotypes of citrus, namely, 80 DAP [10], 105 DAP [29], 118 DAP [31], 120 DAP [32], and 135-150 DAP [28]. The mature seed germination percentage in the two crosses did not differ significantly under in vitro or in vivo conditions. Percent seed germination was recorded for both the crosses under in vitro conditions, but the germination rates in nursery growing media were significantly lower (91.3 and $89.2 \%$ for $\mathrm{RL} \times \mathrm{X}$ and $\mathrm{RL} \times \mathrm{SC}$, respectively). Rescuing the embryos at an immature stage can prevent embryo abortion and results in high recovery of hybrid seedlings. However, the facility or expertise of in vitro embryo rescue may not be available with conventional breeders at all places. Hence, it is also very pertinent to study the possibility of recovering hybrid seedlings from the mature fruits. Percentage data were arcsine transformed before SAS analysis under in vivo and in vitro conditions. The higher germination rates and number of seedlings per seed under in vitro conditions over in vivo conditions may have been due to separate culture of individual embryos, which prevented the competition between embryos during germination and development, as suggested by Sykes [33]. He also concluded that the insufficient nutrient supply during germination from the seed cotyledons was the key factor restricting the germination of embryos. Similarly, Zhu et al. [4] recovered hybrid seedlings by in vitro culture of mature embryos of $C$. sunki $\times$ Poncirus 
trifoliata hybrid seeds. However, in the present study, 6.66 and $3.73 \%$ hybrid seedlings were recovered from the seeds sown in nursery growing media under net house from RL $\times X$ and $R L \times S C$ crosses, respectively, contrary to the results of [4], who did not find any hybrid seedlings from the seeds germinated in soil. A higher number of seedlings per seed recovered under in vitro over the in vivo conditions also substantiated the fact that competition between embryos might have hindered the germination of embryos under in vivo conditions.

Pollen parent also influenced the number of seedlings, with a higher number of seedlings per seed in RL $\times$ SC over RL $\times X$, irrespective of the germination conditions. Culture media also significantly influenced the embryo germination in all the cross combinations. The highest mean embryo germination was recorded with MS medium fortified with ME and $\mathrm{GA}_{3}$ in $\mathrm{RL} \times \mathrm{X}, \mathrm{RL} \times \mathrm{SC}$, and RL $\times$ GT $-64.9 \%, 63.1 \%$ and $63.2 \%$, respectively-over WPM medium-62.1\%, $61.3 \%$ and $60.8 \%$, respectively-irrespective of the stage of embryo rescue and ME levels. The mean embryo germination in MS media with ME did not differ from embryo germination in MS medium fortified with ME and $\mathrm{GA}_{3}$. The concentration of malt extract also had a significant effect on embryo germination. Irrespective of the media composition, the embryo germination percentage increased with increase in the levels of malt extract in the culture media from 0.25 to $0.75 \mathrm{~g} / \mathrm{L}$. Further, increase in malt extract levels to $1.0 \mathrm{~g} / \mathrm{L}$ decreased embryo germination percentage. Addition of $\mathrm{GA}_{3}$ resulted in no significant increase in mean embryo germination in any of the crosses. Among the 12 tested media combinations, MS medium supplemented with $0.75 \mathrm{~g} / \mathrm{L} \mathrm{ME}+1.0 \mathrm{mg} / \mathrm{L} \mathrm{GA}_{3}(\mathrm{G} 3)$ resulted in the highest in vitro embryo germination in all crosses $(71.8 \%$ for $\mathrm{RL} \times \mathrm{X}, 71.7 \%$ for $\mathrm{RL} \times \mathrm{SC}$, and $70.4 \%$ for $\mathrm{RL} \times \mathrm{GT})$ (Table 3); however, there were no significant differences among M2, M3, G2, and W3 media for embryo germination percentage. In all the crosses, namely, $\mathrm{RL} \times \mathrm{X}, \mathrm{RL} \times \mathrm{SC}$, and $\mathrm{RL} \times \mathrm{GT}$, higher mean embryo germination was recorded with MS medium $(64.9 \%, 63.1 \%$, and $62.4 \%$, respectively) over WPM medium $(62.1 \%, 61.3 \%$, and $60.8 \%$, respectively), irrespective of the stage of embryo rescue and ME levels. The mean embryo germination with MS media did not differ from embryo germination in MS medium fortified with $\mathrm{GA}_{3}$.

At the early stage of embryo development, cotyledons are not present in the seed, and thus at the time of embryo germination, germination did not properly occur due to lack of sufficient carbohydrates and nutrients; therefore, there is a requirement for certain supplements such as organic adjuvant (malt extract) and $\mathrm{GA}_{3}$ with MS and WPM for better in vitro embryo germination. Immature or mature zygotic embryos can be excised from their natural growing environment and cultured on an artificial medium in vitro, which is a substitute for the endosperm, allowing continued development and subsequent germination to produce a plant. Medium composition is more critical for immature embryos than mature embryos for their in vitro growth [9]. Malt extract is a source of carbohydrates and plays a specific role in cultures of citrus [34]. Honsho et al. [35] successfully recovered aborting triploid embryos from Hyuganatsu $\times$ Nishiuchi Konatsu on MT media supplemented with malt extract $(0.50 \mathrm{~g} / \mathrm{L})$ along with $\mathrm{GA}_{3}$. Addition of $\mathrm{GA}_{3}$ has been reported to influence the embryo germination and development of Citrus limonia [36], sweet orange [37], and common sour orange $\times$ Carrizo citrange [32]. The requirement of $\mathrm{GA}_{3}$ for in vitro embryo rescue appears to vary with species or varieties, which may be due to different endogenous levels of $\mathrm{GA}_{3}$. In the present study, $\mathrm{GA}_{3}$ had no significant effect on the embryo germination. In citrus, rescued embryos have been generally cultured on Murashige and Skoog medium or Murashige and Tucker medium [9]. Addition of gibberellic acid $\left(\mathrm{GA}_{3}\right)$ enhanced the germination rate of citrus embryos [10,30-32,38]. Medium composition has been considered more important than embryo age for in vitro culture and growth of citrus embryos [9]. Malt extract has been used for improving the germination of hybrid mandarin embryos [13,39]. In mandarins [35], higher recovery of triploid hybrid seedlings with supplementation of culture media with malt extract, $\mathrm{GA}_{3}$, and higher sucrose levels have been reported. The analysis of variance was performed to analyze the variation in embryo germination percentage after $65,80,95,110$, and 125 DAP. The number of days after pollination and culture media had a significant effect on embryo germination in all the three cross combinations (Table 5). 
Table 3. Effect of rescue stage and medium on the germination of $F_{1}$ embryos from three crosses.

\begin{tabular}{|c|c|c|c|c|c|c|c|c|c|c|c|c|c|c|c|c|c|c|}
\hline \multirow{3}{*}{ Media } & \multicolumn{18}{|c|}{ Days after Pollination } \\
\hline & \multicolumn{5}{|c|}{$\mathbf{R L} \times \mathbf{X}$} & \multirow{2}{*}{ Mean } & \multicolumn{5}{|c|}{$\mathbf{R L} \times \mathbf{S C}$} & \multirow{2}{*}{ Mean } & \multicolumn{5}{|c|}{$\mathbf{R L} \times \mathbf{G T}$} & \multirow{2}{*}{ Mean } \\
\hline & 65 & 80 & 95 & 110 & 125 & & 65 & 80 & 95 & 110 & 125 & & 65 & 80 & 95 & 110 & 125 & \\
\hline M1 & 35.8 & 50.3 & 75.3 & 65.3 & 62.7 & $57.9^{\mathrm{d}}$ & 31.5 & 51.2 & 76.6 & 64.9 & 60.8 & 57.0 ef & 33.9 & 48.5 & 74.6 & 63.6 & 60.9 & $56.3^{c}$ \\
\hline M2 & 39.1 & 59.6 & 81.4 & 73.7 & 65.8 & $63.9 \mathrm{abcd}$ & 37.7 & 60.5 & 85.9 & 73.8 & 64.9 & $64.6^{\mathrm{bcd}}$ & 38.7 & 58.7 & 80.0 & 72.2 & 65.5 & $63.0 \mathrm{abc}$ \\
\hline M3 & 43.3 & 66.9 & 92.5 & 77.7 & 70.6 & $70.2^{a b}$ & 41.6 & 65.5 & 97.0 & 75.9 & 70.2 & $70.04^{\mathrm{a}}$ & 41.8 & 65.1 & 90.9 & 75.2 & 69.9 & $68.6^{\mathrm{ab}}$ \\
\hline M4 & 38.3 & 57.0 & 81.8 & 70.4 & 64.7 & $62.5^{\mathrm{bcd}}$ & 33.8 & 57.5 & 79.2 & 68.2 & 62.7 & $60.3^{\text {def }}$ & 37.5 & 56.5 & 79.6 & 68.7 & 64.1 & $61.3 \mathrm{bc}$ \\
\hline G1 & 39.3 & 51.2 & 76.8 & 67.3 & 60.2 & $59.0^{\mathrm{d}}$ & 31.7 & 52.6 & 78.9 & 64.9 & 61.2 & 57.9 ef & 38.6 & 50.1 & 74.8 & 64.7 & 59.0 & $57.5^{\mathrm{c}}$ \\
\hline G2 & 42.7 & 63.1 & 83.6 & 72.5 & 67.1 & $65.8^{\text {abcd }}$ & 38.4 & 61.6 & 87.6 & 73.5 & 67.4 & $65.7 \mathrm{abc}$ & 41.8 & 61.3 & 81.6 & 70.8 & 65.6 & $64.2^{\mathrm{abc}}$ \\
\hline G3 & 44.1 & 68.3 & 96.2 & 78.3 & 72.1 & $71.8^{\mathrm{a}}$ & 43.8 & 66.6 & 97.8 & 78.2 & 72.0 & $67.4^{\mathrm{ab}}$ & 42.1 & 67.5 & 93.7 & 76.7 & 72.0 & $70.4^{\mathrm{a}}$ \\
\hline G4 & 41.8 & 54.2 & 81.9 & 69.9 & 66.2 & $62.8^{\mathrm{bcd}}$ & 35.4 & 57.9 & 82.2 & 68.5 & 63.7 & $61.5^{\text {cde }}$ & 39.6 & 52.9 & 79.7 & 66.9 & 64.9 & $60.8^{b c}$ \\
\hline W1 & 35.0 & 50.9 & 76.7 & 67.9 & 61.2 & $58.4^{\mathrm{d}}$ & 30.5 & 51.0 & 74.6 & 61.9 & 58.8 & $55.3^{\mathrm{f}}$ & 34.5 & 49.2 & 74.9 & 66.7 & 60.6 & $57.2^{c}$ \\
\hline W2 & 38.8 & 55.6 & 81.2 & 72.6 & 64.0 & $62.4^{\mathrm{bcd}}$ & 35.9 & 61.3 & 85.2 & 71.5 & 63.4 & $63.5^{\mathrm{bcd}}$ & 37.6 & 54.5 & 79.7 & 70.3 & 62.7 & $61.0^{b c}$ \\
\hline W3 & 41.8 & 64.4 & 91.1 & 74.2 & 68.8 & $68.1^{a b c}$ & 42.3 & 64.1 & 93.7 & 74.2 & 68.1 & $68.5^{a b}$ & 40.4 & 63.8 & 89.2 & 72.8 & 68.1 & $66.9^{\mathrm{ab}}$ \\
\hline W4 & 35.6 & 51.4 & 78.0 & 69.8 & 63.4 & $59.6^{\mathrm{cd}}$ & 32.9 & 55.4 & 74.8 & 65.2 & 60.4 & $57.7^{\mathrm{ef}}$ & 35.3 & 50.1 & 76.0 & 68.1 & 61.0 & $58.1^{\mathrm{c}}$ \\
\hline Mean & $39.6^{\mathrm{e}}$ & $57.8^{\mathrm{d}}$ & $83.0^{a *}$ & $71.6^{\mathrm{b}}$ & $65.6^{\mathrm{c}}$ & & $36.3^{\mathrm{e}}$ & $58.3^{d}$ & $84.5^{\mathrm{a} *}$ & $69.7^{b}$ & $64.3^{c}$ & & $38.5^{\mathrm{d}}$ & $56.5^{c}$ & $81.2^{\mathrm{a} *}$ & $69.7^{\mathrm{b}}$ & $64.5^{\mathrm{b}}$ & \\
\hline LSD (0.05) & \multicolumn{6}{|c|}{$\begin{array}{c}\text { Media }=8.9 \\
\text { DAP } \times \text { Media }=\text { NS }\end{array}$} & \multicolumn{6}{|c|}{$\begin{array}{c}\text { Media }=5.3 \\
\text { DAP } \times \text { Media }=\text { NS }\end{array}$} & \multicolumn{6}{|c|}{$\begin{array}{c}\text { Media }=8.6 \\
\text { DAP } \times \text { Media }=\text { NS }\end{array}$} \\
\hline
\end{tabular}

${ }^{*}$ Highest average embryo germination. DAP: days after pollination. ${ }^{\text {ae }}$ Significantly different on the basis of the LSD tests $(p=0.05)$ from mean basis.

Table 4. Total number of seeds analyzed, germination rates, and percentage of monoembryonic and polyembryonic seeds from two crosses.

\begin{tabular}{|c|c|c|c|c|c|c|c|c|c|c|c|}
\hline \multirow{2}{*}{ Crosses } & \multicolumn{2}{|c|}{ Number of Seeds Cultured } & \multicolumn{3}{|c|}{ Germination Rate (\%) } & \multicolumn{3}{|c|}{ Polyembryonic (\%) } & \multicolumn{3}{|c|}{ Monoembryonic (\%) } \\
\hline & In Vitro & In Soil & In Vitro & In Soil & Mean & In Vitro & In Soil & Mean & In Vitro & In Soil & Mean \\
\hline$R L \times X$ & 75 & 150 & $100 \pm 0.0^{\mathrm{a}}$ & $91.3 \pm 2.9^{a}$ & $95.7^{\mathrm{a}}$ & $92.0 \pm 5.1^{a}$ & $71.5 \pm 2.4^{\mathrm{a}}$ & $81.8^{\mathrm{a}}$ & $8.0 \pm 0.5^{\mathrm{a}}$ & $28.6 \pm 2.5^{\mathrm{a}}$ & $18.3^{\mathrm{a}}$ \\
\hline $\begin{array}{c}\mathrm{RL} \times \mathrm{SC} \\
\text { Mean }\end{array}$ & 90 & 150 & $\begin{array}{c}100 \pm 0.0^{\mathrm{a}} \\
100.0^{\mathrm{a}}\end{array}$ & $\begin{array}{c}89.3 \pm 2.9^{\mathrm{a}} \\
90.3^{\mathrm{b}}\end{array}$ & $94.7^{\mathrm{a}}$ & $\begin{array}{c}97.7 \pm 2.4^{\mathrm{a}} \\
95.0^{\mathrm{a}}\end{array}$ & $\begin{array}{c}80.7 \pm 4.1^{\mathrm{a}} \\
76.1^{\mathrm{b}}\end{array}$ & $89.2^{\mathrm{a}}$ & $\begin{array}{c}2.2 \pm 0.2^{\mathrm{a}} \\
5.1^{\mathrm{b}}\end{array}$ & $\begin{array}{c}19.4 \pm 1.5^{\mathrm{a}} \\
24.0^{\mathrm{a}}\end{array}$ & $10.8^{b}$ \\
\hline
\end{tabular}

Data are means \pm standard error; ${ }^{\mathrm{a}-\mathrm{b}}$ significantly different on the basis of the LSD tests $(p=0.05)$ from mean basis. 
Table 5. Analysis of variance of germination of embryos from three different crosses at 65, 80, 95, 110, and 125 days after pollination (DAP) on 12 different media compositions.

\begin{tabular}{ccccc}
\hline \multirow{2}{*}{ Source } & DF & \multicolumn{3}{c}{$F$-Value } \\
\cline { 3 - 5 } & & $\mathbf{R L} \times \mathbf{X}$ & $\mathbf{R L} \times \mathbf{S C}$ & $\mathbf{R L} \times \mathbf{G T}$ \\
\hline \multirow{2}{*}{ Media } & \multirow{2}{*}{11} & 2.2 & 7.0 & 2.3 \\
& & 0.0219 & $<.0001$ & 0.0146 \\
\hline \multirow{2}{*}{ Days } & \multirow{2}{*}{4} & 63.1 & 210.7 & 64.4 \\
& & $<0.0001$ & $<0.0001$ & $<0.0001$ \\
\hline \multirow{2}{*}{ Mediax days } & \multirow{2}{*}{44} & 0.1 & 0.2 & 0.1 \\
\hline CV & - & 1.0000 & 1.0000 & 1.0000 \\
\hline
\end{tabular}

DAP: days after pollination; DF: degree of freedom; coefficient of variance (CV) at $5 \%$ level of significance.

\subsection{Polyembryony Analysis}

Higher average polyembryony percentage $(95.0 \%)$ was recorded under in vitro conditions in comparison to $76.1 \%$ in vivo (Table 4 ). The interaction between genotype and seed germination conditions was non-significant. Significantly, a higher percentage of single seedlings was recorded from seeds sown in nursery growing media $(24.0 \%)$ in comparison to seeds grown under in vitro conditions (5.1\%). Genotype had a significant effect on single seedling recovery percentage, with $18.3 \%$ average recorded in RL $\times \mathrm{X}$, which was followed by $10.8 \%$ in $\mathrm{RL} \times \mathrm{SC}$. The interaction between genotype and seed sowing condition revealed the highest monoembryonic seed percent $(28.6 \%)$ in RL $\times \mathrm{X}$ in nursery growing media under in vivo conditions, followed by $19.4 \%$ in $\mathrm{RL} \times \mathrm{SC}$. Significantly, lower monoembryonic seed percentage was recorded under in vitro conditions, with $8 \%$ in $R L \times X$, which was followed by $2.2 \%$ in $\mathrm{RL} \times \mathrm{SC}$. In both $\mathrm{RL} \times \mathrm{X}$ and $\mathrm{RL} \times \mathrm{SC}$ crosses, higher polyembryony and lower monoembryonic seed percentage was recorded under in vitro conditions over nursery growing media. Genotype and germination conditions had a significant effect on monoembryonic vs. polyembryonic seed percentage, with higher monoembryonic seed percentage in $\mathrm{RL} \times \mathrm{X}$ over RL $\times \mathrm{SC}$. The genotypic variation in the number of embryos may have been due to reduction in competition and better nutrient supply to the individual embryos during germination in $\mathrm{RL} \times \mathrm{X}$. The higher number of seedlings per seed with embryo culture confirmed the fact that the zygotic embryos are usually unable to compete with nucellar ones during seed germination. Improper endosperm development also leads to degradation of nucellar embryos, as the endosperm acts as a channel for growth promoters and nutrients from the maternal tissue to the embryo [40,41], and in vitro embryo culture may lead to embryo germination, even under these conditions. The variation in the number of embryos across the citrus species is due to the complex interrelation between genotype and environment [42].

\subsection{Seedling Growth}

The pollen parent, embryo rescue stage, and culture media had significant effects on various parameters of seedling growth, namely, number of leaves, shoot length, number of roots, and root length (Figures 2 and 3). The seedlings from $R L \times X$ crosses had a significantly higher mean root length $(5.7 \mathrm{~cm}$ ) and number of leaves (5.3) over $5.3 \mathrm{~cm}$ and 4.6, respectively, in RL $\times$ SC. However, the genotype of the pollen parent had no significant effect on mean shoot length and number of roots. In the seedlings from RL $\times X$, the highest mean shoot length $(4.7 \mathrm{~cm})$ and root length $(6.3 \mathrm{~cm})$ were recorded from the embryos cultured at $95 \mathrm{DAP}$, which did not differ significantly from the shoot length recorded from the embryos harvested at $65 \mathrm{DAP}$. In $\mathrm{RL} \times \mathrm{SC}$, there was no significant effect stage of embryo rescue on mean shoot and root length. In both crosses, the highest number of roots was recorded from the embryos cultured at 65 DAP.

Irrespective of the stage of embryo culture and ME levels, the highest mean seedling height, leaf number, root length, and number of roots were recorded with MS media fortified with ME and $\mathrm{GA}_{3}$, followed by MS + ME. The lowest seedling height, leaf number, root length, and number of roots 
were recorded in WPM. The increase in the levels of ME from 250 to $750 \mathrm{mg} / \mathrm{L}$ improved seedling growth parameters, namely, seedling height, number of leaves, and root length, in all the crosses. Addition of $\mathrm{GA}_{3}$ improved the seedling height, number of leaves, and root length, however, the results were more pronounced with 500 and $750 \mathrm{mg} / \mathrm{L}$. Among the culture media, for all $\mathrm{RL} \times \mathrm{X}, \mathrm{RL} \times \mathrm{SC}$, and RL $\times$ GT crosses, G3 medium (MS medium supplemented with ME $(0.75 \mathrm{~g} / \mathrm{L})$ and $\left.\mathrm{GA}_{3}\right)$ resulted in the highest shoot lengths $(6.2,6.1$, and $5.3 \mathrm{~cm}$, respectively), number of leaves $(7.1,6.5$, and 6.3 , respectively), and root lengths (8.4, 7.6, and 7.4 , respectively). The average number of seedlings per mature seed was significantly higher under in vitro conditions (3.4) over in vivo seed germination (1.71) in nursery growing media (Table 6).

Table 6. Number of seedlings per seed, survival percent, and plant height (cm) obtained from two culture conditions.

\begin{tabular}{cccccccccc}
\hline Crosses & \multicolumn{2}{c}{ Number of Seedlings Per Seed } & \multicolumn{2}{c}{ Survival \% } & \multicolumn{3}{c}{ Plant Height (cm) } \\
\hline & In Vitro & In Soil & Mean & In Vitro & In Soil & Mean & In Vitro & In Soil & Mean \\
\hline $\mathrm{RL} \times \mathrm{X}$ & $3.1 \pm 0.2^{\mathrm{a}}$ & $1.6 \pm 0.1^{\mathrm{a}}$ & $2.3^{\mathrm{b}}$ & $80.0 \pm 2.1^{\mathrm{a}}$ & $88.7 \pm 2.2^{\mathrm{a}}$ & $84.3^{\mathrm{a}}$ & $22.8 \pm 3.5^{\mathrm{a}}$ & $21.3 \pm 4.2^{\mathrm{a}}$ & $22.1^{\mathrm{a}}$ \\
$\mathrm{RL} \times \mathrm{SC}$ & $3.7 \pm 0.2^{\mathrm{a}}$ & $1.9 \pm 0.1^{\mathrm{a}}$ & $2.8^{\mathrm{a}}$ & $79.3 \pm 2.6^{\mathrm{a}}$ & $85.3 \pm 2.1^{\mathrm{a}}$ & $82.3^{\mathrm{a}}$ & $29.6 \pm 6.6^{\mathrm{a}}$ & $19.9^{\mathrm{a}} \pm .1^{\mathrm{a}}$ & $24.7^{\mathrm{a}}$ \\
Mean & $3.4^{\mathrm{a}}$ & $1.7^{\mathrm{b}}$ & & $79.7^{\mathrm{a}}$ & $87.0^{\mathrm{a}}$ & & $25.4^{\mathrm{a}}$ & $21.4^{\mathrm{a}}$ & \\
\hline
\end{tabular}

Data are means \pm standard error; ${ }^{\mathrm{a}-\mathrm{b}}$ significantly different on the basis of the LSD tests $(p=0.05)$ from mean basis.

The cross RL $\times$ SC had a significantly higher number of seedlings per seed (2.8) over RL $\times$ X (2.3), irrespective of the seed germination conditions. There was no significant effect of growing conditions and pollen parent on the plant height of the hybrid seedlings. Further, the interaction between the growing conditions and genotype was not significant for survival percentage and number of seedlings per seed. Similarly, Perez-Tornero and Porras [28] observed variation of shoot and root length of embryos from different species with four different media. Viloria et al. [13] also reported that root length was affected by medium for acid fruit, and that MS medium significantly enhanced root growth. The low proportion of multifoliate hybrid seedlings from the embryos cultured at early (65 and $80 \mathrm{DAP}$ ) and late (110 and $125 \mathrm{DAP})$ fruit developmental stages may have been due to embryo injury and abortion, respectively.

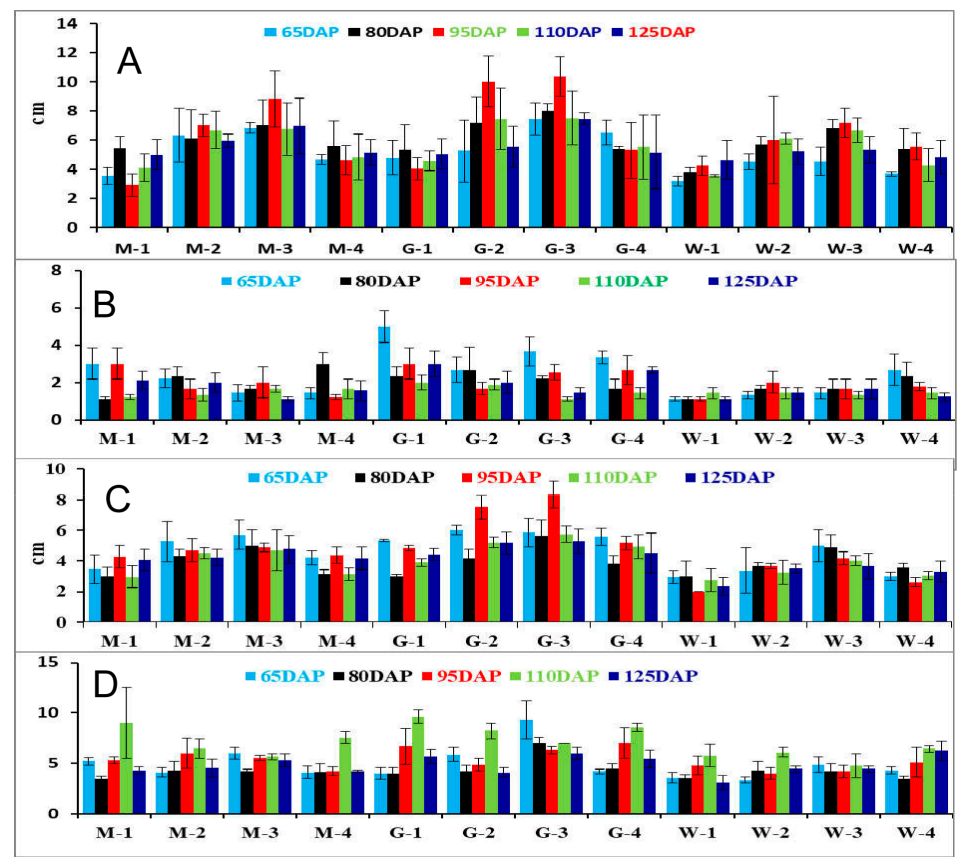

Figure 2. Root length (A), number of roots (B), shoot length (C), and number of leaves (D) of the seedlings from immature embryos of the controlled crossing between RL and X grown in different combinations of the medium. 


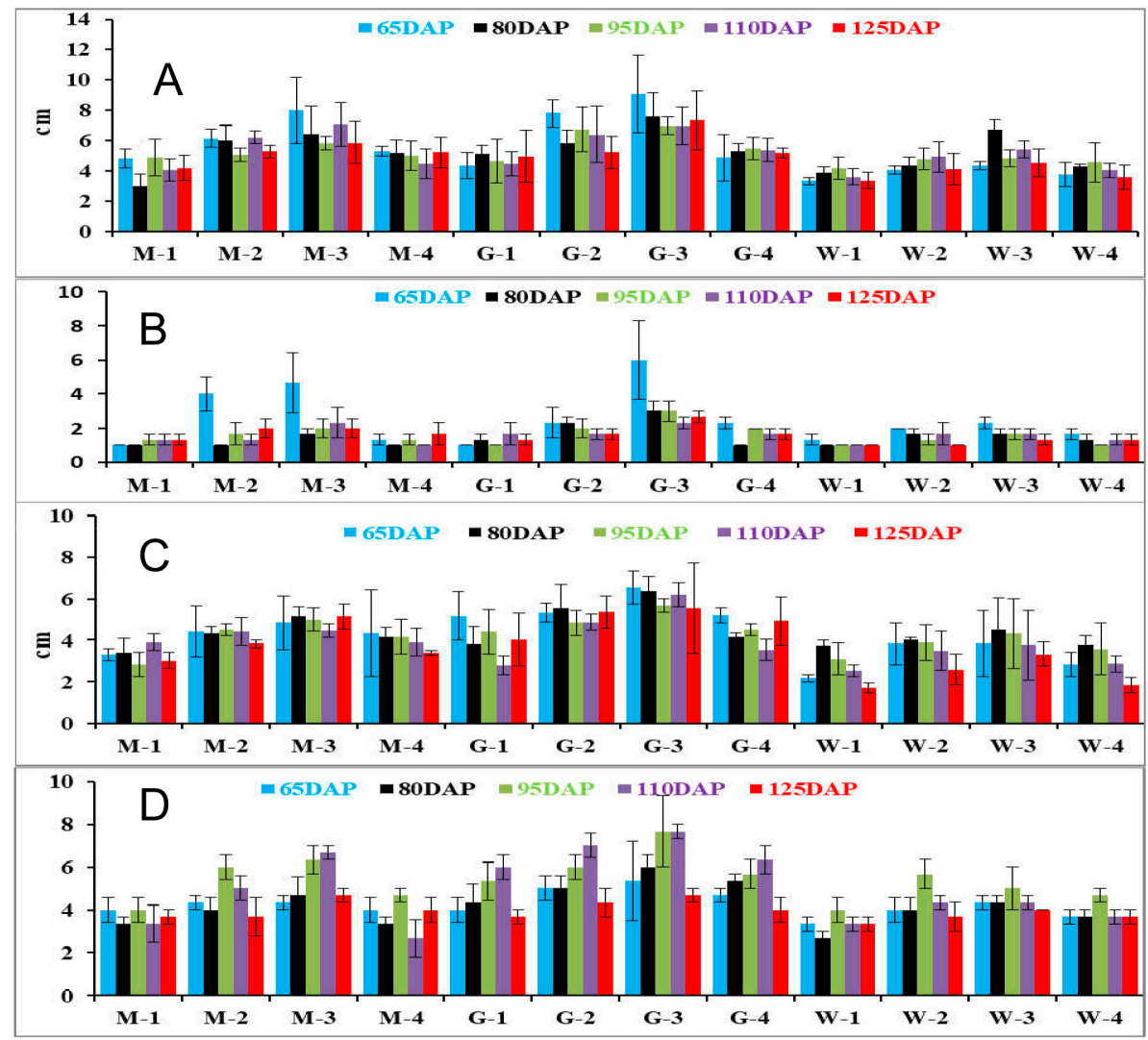

Figure 3. Root length (A), number of roots (B), shoot length (C), and number of leaves (D) of the seedlings from immature embryos of the controlled crossing between RL and SC grown in different combinations of the medium.

\subsection{Proportion of Hybrid Seedlings Identified by Morphological Marker}

In both cross combinations, the minimum proportion of hybrid seedlings with multifoliate leaves (Table 2) were recorded from the immature embryos cultured at 65 DAP $(22.2 \%$ in RL $\times$ X and $24.1 \%$ in $\mathrm{RL} \times \mathrm{SC})$, which increased with the stage of embryo culture to the highest levels at $95 \mathrm{DAP}(48.5 \%$ in $\mathrm{RL} \times \mathrm{X}$ and $56.7 \%$ in $\mathrm{RL} \times \mathrm{SC}$ ). The proportion of hybrid seedlings decreased when the embryos were cultured after 95 DAP until the last stage of observation (125 DAP).

Significantly higher proportion of multifoliate seedlings (26.9\%) was recovered by in vitro culture method over in vivo conditions (5.2\%) from mature seeds. The pollen parent had no significant effect on the proportion of multifoliate seedlings. While studying the interaction between growing conditions and genotype, we recorded a higher proportion of multifoliate seedlings (31.1\%) in RL $\times$ SC via in vitro culture, followed by $22.7 \%$ multifoliate seedlings for $R L \times X$ by the same method. The excision of embryos at the early fruit developmental stage is difficult, and it is not easy to isolate small embryos without injury [9]. The embryos excised at an early stage have less chance of survival and require complex medium for growth and germination. Further, there is a risk of embryo abortion when the embryos are dissected very late [43]. There seems to be an optimal fruit growth stage for higher recovery of hybrid seedlings under in vitro conditions, which may vary with the genotype [12,13]. Kurt and Ulger [32] cultured the embryos from a cross of Common sour orange $\times$ Carrizo citrange at three fruit developmental stages $(80,100$, and 120 DAP). Though the proportion of trifoliate seedlings varied with fruit developmental stage, the lowest proportion of trifoliate seedlings were recorded at $100 \mathrm{DAP}$, with higher percentage of trifoliate seedlings at 80 and 120 DAP. The differences in the present findings, where continuous decrease of proportion of trifoliate seedlings was recorded when the embryos were cultured at $95 \mathrm{DAP}$, may have been due to the embryo abortion due to advancement in fruit developmental stage and genotypic differences. 


\subsection{Verification of Zygotic Seedlings Using SSR Markers}

All the seedlings with multifoliate leaves from immature and mature seeds were identified as hybrid seedlings by SSR analysis. Two SSR markers were employed to identify the zygotic seedlings from the $F_{1}$ population of both the crosses. Zygotic seedlings depicting marker alleles were different from that of the mother at any discriminating locus, whereas seedlings with the same banding patterns as the female parent were identified as nucellar seedlings. SSRs are codominant and multiallelic markers that usually display high levels of polymorphism and have a high degree of reliability and reproducibility [44]. When a population is derived from a cross, all of the zygotic individuals show a genotype different from that of the mother at any discriminating locus, provided that the father has alleles different than those of the mother [45]. The F29 or F87 primer exhibited rich polymorphism and allele segregation was there among offspring (Figures 4 and 5).

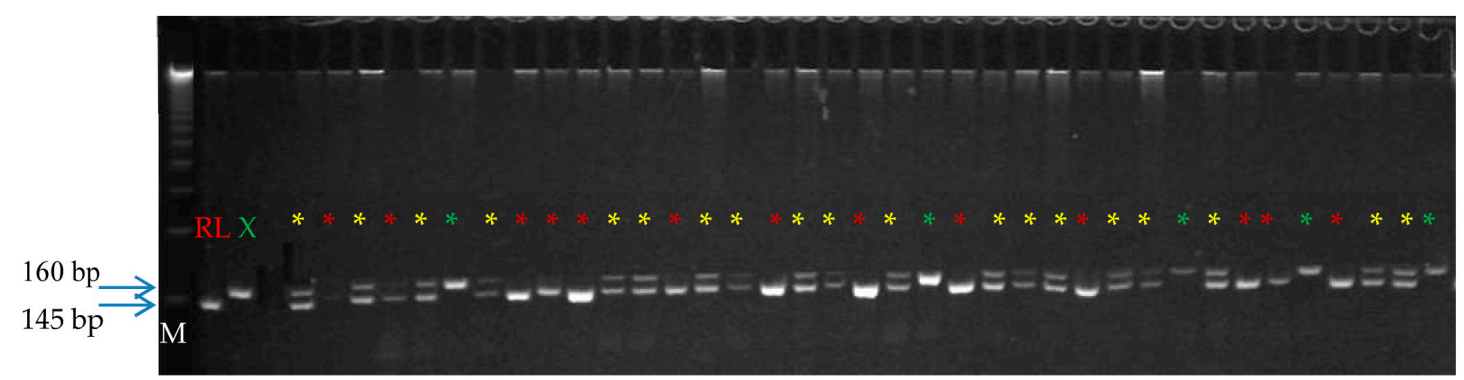

Figure 4. PAGE gel showing PCR amplification using DNAs from seedling of RL $\times$ X: yellow labeled zygotic seedlings with bifoliate and trifoliate leaves; red labeled nucellar seedlings; and green labeled zygotic seedlings with extra allele (primer F29). M is molecular marker of $50 \mathrm{bp}$.

Both female and male parents were heteroallelic for the locus, and a total of two alleles appeared on the F29 locus in the $F_{1}$ population of RL $\times$ X (Figure 4) and four alleles appeared on the F87 locus in the $\mathrm{F}_{1}$ population of RL $\times \mathrm{SC}$ (Figure 5). In both the crosses, out of the 170 multifoliate seedlings from immature and mature seeds, only 161 were zygotic, while the other 9 seedlings were not confirmed to be zygotic by the two (F87 and F29) SSR markers. The SSR analysis of unifoliate $F_{1}$ seedlings with five SSR primers differentiated seedlings into zygotic and nucellar seedlings (Table 7). In three crosses, the SSR primer F29 showed the highest efficiency in identifying the unifoliate zygotic seedlings $(15,14$, and 9 hybrid seedlings per 50 seeds in $R L \times X, R L \times S C$, and $R L \times G T$, respectively). In RL $\times X$ crosses, the primer CCSME31 identified 13 hybrid unifoliate seedlings per 50 seeds, and it was followed by 11 seedlings by TAA1. In RL $\times$ SC, 12 hybrid unifoliate seedlings per 50 seeds were identified by SSR primer F87 and CCSMEc4. In RL $\times$ GT crosses, the primer TAA1 identified 11 hybrid unifoliate seedlings per 50 seeds, and it was followed by 10 seedlings by CCSME31. Similarly, Kim et al. [46] identified 7 zygotic embryos out of 58 seeds at 90 DAP, and 1 at 145 DAP and 4 at 180 DAP out of 98 and 97 seeds, respectively.

The dominant "trifoliate leaf" trait over the recessive unifoliate leaf trait makes it easy to identify the first-generation hybrid seedlings in crosses between unifoliate citrus and trifoliate orange male parents [33]. In light of the presence of unifoliate zygotic seedlings in the hybrids from the crosses between mandarins and hybrids of trifoliate orange (Swingle citrumelo) as male parent, multifoliate leaf trait cannot be considered as the sole reliable marker [14]. Several studies have reported various zygotic frequencies (0-87\%) in other citrus genotypes, depending on the maternal and pollen genotypes $[25,45,47,48]$. 


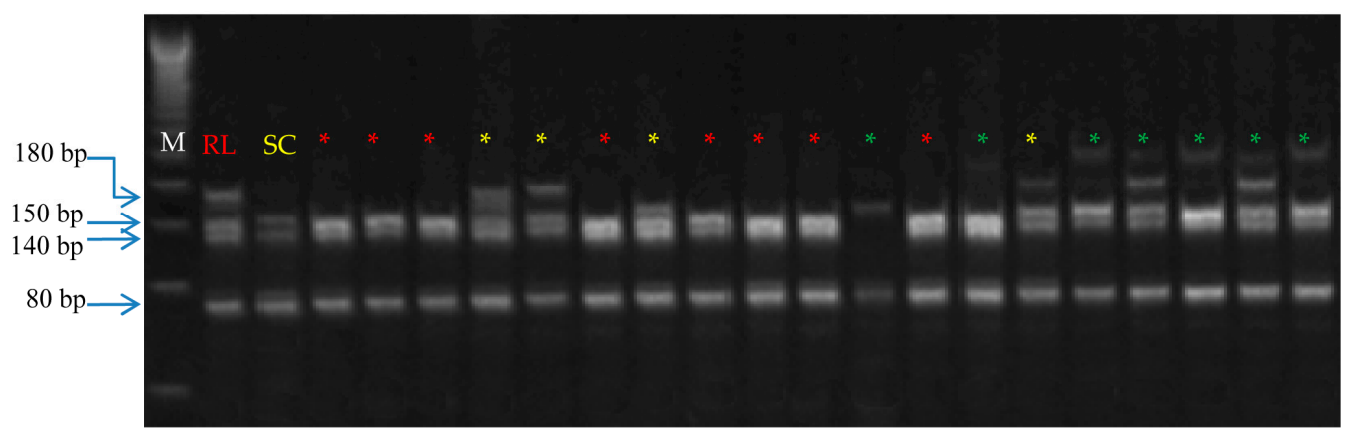

Figure 5. PAGE gel showing PCR amplification of F87 primer using DNAs from seedlings of RL $\times$ SC: yellow labeled zygotic seedlings; red labeled nucellar seedlings; and green labeled extra alleles of zygotic seedlings. $\mathrm{M}$ is molecular marker of $50 \mathrm{bp}$.

Andrade-Rodriguez et al. [49] reported that the zygotic embryos were located near the micropylar end in mature seeds of Citrus volkameriana. However, in sour orange seeds extracted after 125-220 DAP, zygotic embryo could not be distinguished from nucellar embryos on the basis of embryo size and position in the seed [50]. Hence, morphological selection of zygotic embryo on the basis of size and location is not feasible in mature citrus seeds. Further, the scarcity of morphological markers necessitates the use of other reliable techniques for identification of zygotic seedlings. DNA markers are a very reliable tool to unmistakably identify the zygotic seedlings [4]. SSR markers have been used to identify the hybrid seedlings in citrus $[10,15,16]$. Single-nucleotide polymorphism (SNP) markers have also been used in citrus for the identification of zygotic seedlings in hybrids involving trifoliate orange [4,14], however, they are expensive and not applicable in every laboratory [17].

Table 7. Identification of zygotic seedlings with five SSR markers in RL $\times$ X (75 seedlings), RL $\times$ SC, and RL $\times$ GT (84 seedlings) crosses from unifoliate leaf seedlings.

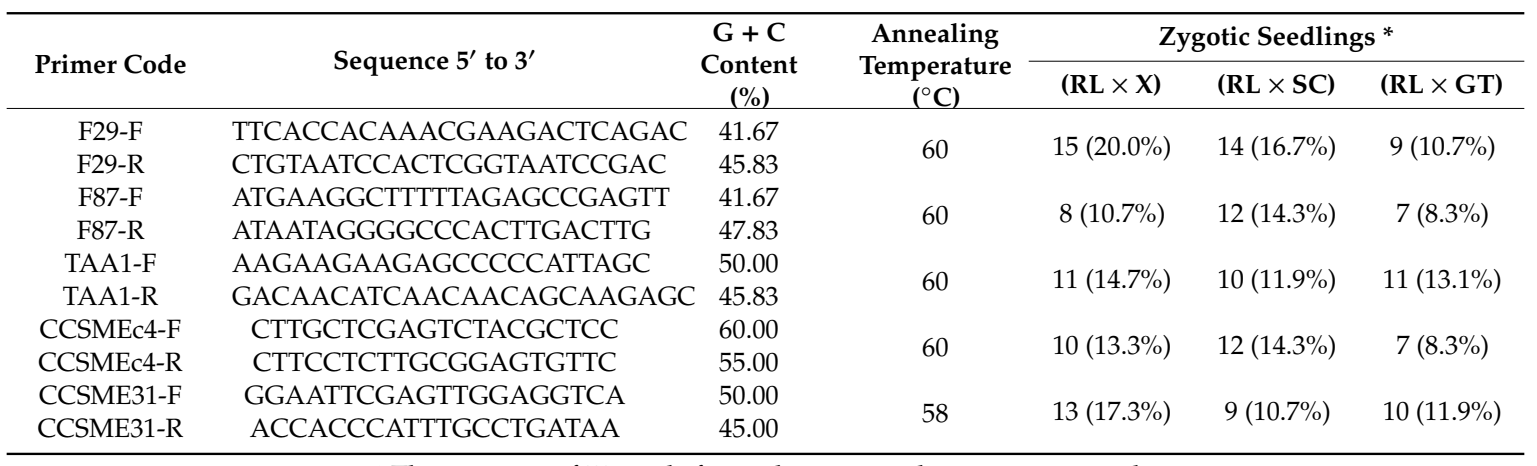

* The progeny of 50 seeds for each cross combination was used.

\section{Conclusions}

In all the three citrus cross combinations of rough lemon with Swingle citrumelo, X-639 citrandarin, and GouTou Cheng, the highest recovery of zygotic seedlings was recorded at 95 DAP. A higher proportion of multifoliate seedlings $(26.9 \%)$ was recovered by in vitro culture method over in vivo conditions $(5.2 \%)$ from mature seeds, indicating the greater recovery of hybrids. The pollen parent, embryo rescue stage, and culture media had significant effects on seedling growth of hybrids. SSR primers F29, TAA1, CCSME31, and CCSMEc4 showed higher efficiency in identifying zygotic seedlings from unifoliate seedlings in all cross combinations. The hybrid seedlings with multifoliate leaves were identified by SSR F87 and F29.

Author Contributions: Designed the study: H.S.D. and P.C.; field experiments: J.S., A.T., and G.S.S.; statistical analyses: J.S. and A.T.; manuscript writing: J.S., A.T., G.S.S., and F.G.G.J. All authors have read and agreed to the published version of the manuscript. 
Funding: This research received no external funding.

Acknowledgments: We are grateful to the Department of Fruit Science, College of Horticulture and Forestry, for providing pollen for hybridization. We also thank Gurdev Singh of Khush Laboratories, School of Agricultural Biotechnology, Punjab Agricultural University, Ludhiana, India, for providing the Molecular Biology Laboratory facilities.

Conflicts of Interest: The authors declare no conflict of interest.

\section{References}

1. FAOSTAT Faostat Statistical Database. Food and Agriculture Organization of the United Nations. 2018. Available online: http://faostat.fao.org/faostat (accessed on 13 March 2020).

2. Cheng, F.S.Z.; Roose, M.L. Origin and inheritance of dwarfing by the citrus rootstock Poncirus trifoliata 'Flying Dragon'. J. Am. Soc. Hortic. Sci. 1995, 120, 286-291. [CrossRef]

3. Medina-Urrutia, V.M. Rootstock research for Mexican lime trees (Citrus aurantifolia Swingle) in Mexico: An overview. In Proceedings of the International Society Citriculture, Wuhan, China, 26-30 October 2008.

4. Zhu, S.; Wu, B.; Ma, Y.; Chen, J.; Zhonga, G. Obtaining citrus hybrids by in vitro culture of embryos from mature seeds and early identification of hybrid seedlings by allele-specific PCR. Sci. Hortic. 2013, 161, 300-305. [CrossRef]

5. Davies, F.S.; Albrigo, L.G. Citrus; CAB International: Wallingford, UK, 1994.

6. Louzada, E.S.; Del, R.H.S.; Xia, D. Preparation and fusion of Citrus sp. microprotoplasts. J. Am. Soc. Hortic. Sci. 2002, 127, 484-488. [CrossRef]

7. Ollitrault, P.; Dambier, D.; Froelicher, Y.; Carreel, F.; Hont, A.; Luro, F. Somatic hybridization potential for citrus germplasm utilization. Cah. Agric. 2000, 9, 223-236.

8. Soost, R.K.; Roose, M.L. Citrus. In Fruit Breeding; Janick, J., Moore, J.N., Eds.; Wiley: New York, NY, USA, 1996; pp. 257-323.

9. Shen, X.; Gmitter, F.G.; Grosser, J.W. Immature embryo rescue and culture. Methods Mol. Boil. 2011, 710, 75-92.

10. Tan, M.J.; Song, J.; Deng, S. Production of two mandarin $\times$ trifoliate orange hybrid population via embryo rescue with verification by SSR analysis. Euphytica 2007, 157, 155-160. [CrossRef]

11. Yi, H.L.; Deng, X.X.; Fu, C.H. Application of embryo rescue techniques in fruit crops. J. Fruit Sci. 2001, 18, 224-228.

12. Jaskani, M.J.; Khan, I.A.; Khan, M.M. Fruit set, seed development and embryo germination in interploid crosses of citrus. Sci. Hortic. 2005, 107, 51-57. [CrossRef]

13. Viloria, Z.; Grosser, J.W.; Bracho, B. Immature embryo rescue, culture and seedling development of acid citrus fruit derived from interploid hybridization. Plant Cell Tissue Organ Cult. 2005, 82, 159-167. [CrossRef]

14. Caruso, M.; Distefano, G.; Paolo, D.P.; Malfa, S.L.; Russo, G.; Gentile, A.; Recupero, G.R. High resolution melting analysis for early identification of citrus hybrids: A reliable tool to overcome the limitations of morphological markers and assist rootstock breeding. Sci. Hortic. 2014, 180, 199-206. [CrossRef]

15. Oliveira, A.C.; Garcia, A.N.; Cristofani, M.; Machado, M.A. Identification of citrus hybrids through the combination of leaf apex morphology and SSR markers. Euphytica 2002, 128, 397-403. [CrossRef]

16. Rao, M.N.; Soneji, J.R.; Chen, C.; Huang, S.; Gmitter, F.G., Jr. Characterization of zygotic and nucellar seedlings from sour orange-like citrus rootstock candidates using RAPD and EST-SSR markers. Tree Genet. Genomes 2008, 4, 113-124.

17. Dettori, M.T.; Micali, S.; Giovinazzi, J.; Scalabrin, S.; Verde, I.; Cipriani, G. Mining microsatellites in the peach genome: Development of new long-core SSR markers for genetic analyses in five Prunus species. Springer Plus 2015, 10, 337. [CrossRef] [PubMed]

18. Murashige, T.; Skoog, F. A revised medium for rapid growth and bio assays with tobacco tissue cultures. Physiol. Plant 1962, 15, 473-497. [CrossRef]

19. Lloyd, G.; Mc-Cown, B.H. Commercially feasible micropropagation of mountain laurel, (Kalmia latifolia) by use of shoot tip culture. Int. Plant Prop. Soc. Comb. Proc. 1980, 30, 421-427.

20. Doyle, J.J.; Doyle, J.L. Isolation of plant DNA from fresh tissue. Focus 1990, 12, 13-15.

21. Chen, C.; Zhou, P.; Choi, Y.A.; Huang, S.; Gmitter, F.G., Jr. Mining and characterizing microsatellites from citrus ESTs. Theor. Appl. Genet. 2006, 112, 1248-1257. [CrossRef] 
22. Kaur, M. Development of Citrus Rootstock Hybrids and Their Molecular Characterization. Ph.D. Thesis, Punjab Agricultural University, Ludhiana, India, 15 July 2017.

23. Palmieri, D.A.; Novelli, V.M.; Bastianel, M.; Cristofani-Yaly, M.; Astúa-Monge, G.; Carlos, E.F.; Oliveira, A.C.; Machado, M.A. Frequency and distribution of microsatellites from ESTs of citrus. Genet. Mol. Biol. 2007, 30, 1009-1018. [CrossRef]

24. Singh, J.; Dhaliwal, H.S.; Thakur, A.; Chhuneja, P.; Sidhu, G.S.; Singh, R. Morphological and genetic diversity in citrus genotypes to substantiate rootstock breeding for root rot resistance. Indian J. Hortic. 2017, 74, 326-333. [CrossRef]

25. Yildiz, E.; Kaplankiran, M.; Demirkeser, T.H.; Uzun, A.; Toplu, C. Identifcation of zygotic and nucellar individuals produced from several citrus crosses using SSRs markers. Not. Bot. Hortic. Agrobot. 2013, 2, 478-484. [CrossRef]

26. Cooper, W.C.; Reece, P.C.; Furr, J.R. Citrus breeding in Florida: Past, present and future. Proc. Fla. State Hortic. Soc. 1962, 75, 5-13.

27. Soost, R.K.; Cameron, J.W. Citrus. In Advances in Fruit Breeding; Janick, J., Moore, J.N., Eds.; Purdue University: West Lafayette, IN, USA, 1975; pp. 507-540.

28. Perez-Tornero, O.; Porras, I. Assessment of polyembryony in lemon: Rescue and in vitro culture of immature embryos. Plant Cell Tissue Organ Cult. 2008, 93, 173-180. [CrossRef]

29. Scarano, M.T.; Tusa, N.; Abbate, L.; Lucretti, S.; Nardi, L.; Ferrante, S. Flow cytometry, SSR and modified AFLP markers for the identification of zygotic plantlets in backcrosses between 'Femminello' lemon cybrids ( $2 \mathrm{n}$ and $4 \mathrm{n}$ ) and a diploid clone of 'Femminello' lemon (Citrus limon L. Burm. F.) tolerant to Mal secco disease. Plant Sci. 2005, 164, 1009-1017. [CrossRef]

30. Turgutoglu, E.; Kurt, S.; Demir, G. Effect of $\mathrm{GA}_{3}$ concentrations in basal medium on embryos germination of Cleopatra mandarin $\times$ Carrizo citrange and Cleopatra mandarin $\times$ Flying Dragon. Ekin J. Crop Breed. Genet. 2015, 1, 17-19.

31. Chagas, E.A.; Pasqual, M.; Ramos, J.D.; Pio, L.A.S.; Dutra, L.F.; Cazetta, J.O. Activated charcoal and gibberellic acid concentrations on immature embryos culture. Sci. Agrotechnol. 2005, 29, 1125-1131.

32. Kurt, S.; Ulger, S. Production of common sour orange $\times$ Carrizo citrange hybrids using embryo rescue. Int. J. Fruit Sci. 2014, 14, 42-48. [CrossRef]

33. Sykes, S.R. Characterisation of citrus rootstock germplasm introduced as seeds to Australia from the People's Republic of China. Sci. Hortic. 2011, 127, 298-304. [CrossRef]

34. George, E.F.; Hall, M.A.; De Klerk, G.J. Plant propagation by tissue culture- The background. In The Components of Plant Tissue Culture Media I: Macro and Micro-Nutrients; George, E.F., Hall, M.A., de Klerk, G., Eds.; Springer Publishers: Dordrecht, The Netherlands, 2008; pp. 65-113.

35. Honsho, C.; Tsuruta, K.; Ryuto, K.; Sakata, A.; Kuroki, S.; Nishiwaki, A.; Tetsumura, T. Characterization of seed and embryo abortion during fruit development in citrus cultivars pollinated by 'Nishiuchi Konatsu' (Citrus tamurana) and a preliminary trial of embryo rescue in aborting embryos. Acta Hortic. 2015, 1065, 181-186. [CrossRef]

36. Ribeiro, V.G.; Sanabio, D.; Souza, C.N.D.; Lopes, P.S.N.; Bocardo, M.R.; Pasqual, M. Effects of gibberellic acid $\left(\mathrm{GA}_{3}\right)$ and activated coal on in vitro culture of Citrus limonia Osbeck $\times$ Poncirus trifoliata L. Raf. embryos. Pesq. Agropecu. Bras. Brasilia 2000, 35, 27-30. [CrossRef]

37. Chagas, E.A.; Pasqual, M.; Ramos, J.D.; Cardoso, P.; Cazetta, J.O.; Figueiredo, M.A.D. Development of globular embryos from the hybridization between 'Pera Rio' sweet orange and 'Ponca' mandarin. Rev. Bras. Frutic. 2003, 25, 483-488. [CrossRef]

38. Ollitrault, P.; Guo, W.W.; Grosser, J.W. Somatic hybridization. In Citrus Genetics, Breeding and Biotechnology; Khan, I.A., Ed.; CABI Publishing: Wallingford, UK, 2007; pp. 235-260.

39. Aleza, P.; Juarez, J.; Ollitrault, P.; Navarro, L. Polyembryony in non-apomictic citrus genotypes. Ann. Bot. 2010, 106, 533-545. [CrossRef]

40. Gupta, P.; Shivanna, K.R.; Mohan Ram, H.Y. Apomixis and polyembryony in the guggul plant, Commiphora wightii. Ann. Bot. 1996, 78, 67-72. [CrossRef]

41. Yeung, E.C.; Meinke, D.W. Embryogenesis in angiosperms: Development of the suspensor. Plant Cell Rep. 1993, 5, 1371-1381. [CrossRef]

42. Kishore, K.; Monika, N.; Rinchen, D.; Lepcha, B.; Pandey, B. Polyembryony and seedling emergence traits in apomictic citrus. Sci. Hortic. 2012, 138, 101-107. [CrossRef] 
43. Raghavan, V. Some reflections on double fertilization, from its discovery to the present. New Phytol. 2003, 159, 565-583. [CrossRef]

44. Morgante, M.; Olivieri, A.M. PCR-amplified microsatellite as markers in plant genetics. Plant J. 1993, 3, 175-182. [CrossRef]

45. Ruiz, C.; Breto, M.P.; Asins, M.J. A quick methodology to identify sexual seedlings in citrus breeding programs using SSR markers. Euphytica 2000, 112, 89-94. [CrossRef]

46. Kim, M.; Kim, S.H.; Kim, H.B.; Park, Y.C.; Song, K.J. Some factors affecting the efficiency of hybrid embryo rescue in the 'Shiranuhi' mandarin. Hortic. Sci. Technol. 2020, 38, 271-281.

47. Yun, J.U.; Yang, H.B.; Jung, Y.H.; Yun, S.H.; Kim, K.S.; Kim, C.S.; Song, K.J. Identification of zygotic and nucellar mandarin seedling using randomly amplified polymorphic DNA. Hortic. Environ. Biotechnol. 2007, 48, 171-175.

48. Jin, S.B.; Yun, S.H.; Park, J.H.; Park, S.M.; Koh, S.W.; Lee, D.H. Early identification of citrus zygotic seedlings using pollen-specific molecular markers. Korean J. Hortic. Sci. Technol. 2015, 33, 598-604. [CrossRef]

49. Andrade-Rodriguez, M.; Villegas-Monter, A.; Carrillo-Castaneda, G.; Garcia-Velazquez, A. Polyembryony and identification of Volkamerian lemon zygotic and nucellar seedlings using RAPD. Pesq. Agropecu. Bras. 2004, 39, 551-559. [CrossRef]

50. Carimi, F.; de Pasquale, F.; Puglia, A.M. In vitro rescue of zygotic embryos of sour orange, Citrus aurantium L., and their detection based on RFLP analysis. Plant Breed. 1998, 117, 261-266. [CrossRef]

Publisher's Note: MDPI stays neutral with regard to jurisdictional claims in published maps and institutional affiliations. 